\title{
Correction to: Health Care Transition Planning Among Youth with ASD and Other Mental, Behavioral, and Developmental Disorders
}

\author{
Benjamin Zablotsky ${ }^{1}$ [D $\cdot$ Jessica Rast ${ }^{2} \cdot$ Matthew D. Bramlett $^{1} \cdot$ Paul T. Shattuck $^{2}$
}

Published online: 9 March 2020

○) Springer Science+Business Media, LLC, part of Springer Nature 2020

\section{Correction to: Maternal and Child Health Journal https://doi.org/10.1007/s10995-019-02858-6}

In the original publication of the article, Figure 1 included footnotes which duplicated information appearing in the figure caption. Therefore the notes of "NOTES: ASD = autism spectrum disorder; MBDD = mental, behavioral, or developmental disorder. Indicators presented are unadjusted estimates. ${ }^{\mathrm{x}}$ Significantly different than youth with autism spectrum disorder based on adjusted odds ratio $(p<.05){ }^{\mathrm{y}}$ Significantly different than youth with other mental, behavioral, or developmental disorders based on adjusted odds ratio $(p<.05)$." have been removed. The figure 1 appearing in the original version of the article has been corrected.
Publisher's Note Springer Nature remains neutral with regard to jurisdictional claims in published maps and institutional affiliations.

The original article can be found online at https://doi.org/10.1007/ s10995-019-02858-6.

Benjamin Zablotsky

bzablotsky@cdc.gov

1 Centers for Disease Control and Prevention, National Center for Health Statistics, 3311 Toledo Road, Hyattsville, MD 20782, USA

2 A.J. Drexel Autism Institute, Drexel University, Philadelphia, PA, USA 